\title{
The Effects of the Sling Strap Height on Trunk and hip Muscle Activation During the Bridging Exercise with Sling
}

\author{
Kwang-Su Kim¹, Hwa-Kyung Shin² \\ ${ }^{1}$ Graduate School of Medical Science, Catholic University of Daegu, Daegu; ${ }^{2}$ Department of Physical Therapy, College of Medical Health, Catholic \\ University of Daegu, Daegu, Korea
}

Purpose: The objective of this study was to identify determine the effect of the strap height on muscular activity of trunk and lower limbs muscles during bridging exercise with a sling.

Methods: The subjects of the study were 17 healthy male adults. In order to For measurement of muscular activity, body surfaces electrodes were placed on areas including erector spinae, multifidus muscles, gluteus maximus, and hamstring and the results was were recorded based on three different heights of strap, which are Levels 1, 2, and 3.

Results: The muscular activities in erector spinae, multifidus muscle, and gluteus maximus were significantly different in at all three heights $(p<0.05)$., Level 3 showed the highest the compared to Levels 1 and 2 . In hamstring muscle, there was significant difference in levels 1 and 2 , also and levels 1 and $3(p<0.05)$. Bbut there was no significant difference between 2 and 3 . The ration of muscular activities in multifidus muscles/erector spinae and gluteus maximus/hamstrings were significantly different for all three strap heights $(\mathrm{p}<0.05)$. Also, Level 3 showed higher than 1 or 2.

Conclusion: The results of this study suggests to adjustment of the level III, that which has high activity level of multifidus and gluteus maximus affecting trunk stability during bridging exercise using a sling.

Keywords: Bridging exercise, Electromyography, Trunk muscles

\section{서 론}

최근 근골격계 질환의 재활목표는 근육의 불균형과 운동 조절의 문 제로 야기되는 근력과 근지구력의 감소로 인해 약화된 근육의 정확 한 동원과 운동 조절능력에 초점이 맞춰져 있다. 또한 재활훈련으로 써 치료적 운동은 근육의 기능향상을 위한 필수적인 접근법으로 여 겨지고 있다. 치료적 운동의 효과는 신경계에서 감각정보 유입의 변 화와 염증을 감소시키며, 조직의 회복과 재생을 증가시켜 통증을 완 화시키고 근육의 정상적인 기능회복 등의 장점이 있다. 최근의 치료 에서는 능동적 치료 참여가 수동적인 방법에 의한 치료보다 더 효과 적이며, 특히 능동적 참여를 전제로 하는 신경근 조절 운동은 환자의 치료에 있어 매우 중요하다.' 이러한 추세에서 운동유형은 고유수용 기의 자극과 신경근 조절을 향상시키기 위하여 체중부하운동인 닫 힌 사슬 근력강화운동(close chain exercise)을 적용하는 운동의 중요
성이 증가하고 있다. 닫힌 사슬 근력강화운동의 대표적인 예는 전단 력, 관절압력의 증가, 관절의 안정성과 일치성을 증가, 동적 안정성의 증가, 그리고 고유수용기의 자극 등이 있는 체중 부하성 운동이다.2,3 임상에서는 안정화근육들의 활성을 증가시키기 위해 닫힌 사슬 근력강화운동의 도구인 슬링이 주로 사용되고 있으며, 슬링 운동의 장점으로는 근력 강화 운동, 신경근 조절, 그리고 안정화 운동으로 효 과적이며 매우 쉽게 이용될 수 있다. 쿠션이나 슬링과 같이 불안정한 지지면 에서의 안정화 운동은 체간근의 근활성도가 더 높게 나타나 는 것을 보고되고 있으며, 슬링을 이용한 닫힌 사슬 근력운동을 점진 적으로 적용하였을 때 요통환자의 고유수용성 감각과 근력이 증가 되었음을 보고하고 있다. 슬링을 이용한 운동은 지렛대의 조절을 통 한 이론적 개념과 약화 고리(waek link)의 개념을 이용한 진단 및 운 동 처방을 하며 진단은 통증의 발생과 운동 자세의 정확성, 그리고 운동 시 좌우측의 대칭성을 비교하여 문제점을 찾아서 이를 기준으 
로 적절한 운동단계를 적용하여 치료하는 과정을 다루고 있으며, 임 상에서 많이 시행되는 물리치료 기법들이 대부분 수동적인 접근법 인 것에 비해 능동적 운동방법이라는 의미에서 그 의미가 크다고 할 수있다.

한편, 닫힌 사슬 근력강화운동의 교각자세 운동(bridging exercise) 은 물리치료 프로그램에서 엉덩관절 폄근 강화와 체간의 안정성 증 가에 가장 흔하게 사용되는 운동이며, 누운 자세에서 실시하므로 주 로 재활 초기에 적용하며, 부하의 정도, 지지면의 상태 그리고 발의 위 치의 변화에 따라 체간과 하지 근육의 활성도를 다양화 할 수 있는 운동이다. 그리고 하지근육과 체간근육의 신경근 조절능력을 높이 기 위해 임상적으로 중요하다고 알려져 있고, 요추골반부와 체간의 기능적 안정성을 강화시키기 위한 좋은 운동이며, 큰볼기근(gluteus maximus)과 넙다리뒤근육(hamstrings)의 근력을 증진시키는 방법으 로 많이 사용되고 있다. 교각자세 운동은 체중이 부하된 상태에서 무 릎 서기 자세를 수행하는 중요한 동작이며, 앉은 자세에서 일어나는 조절능력을 발달시키며, 보행시 입각기 준비를 위한 하부 척추와 엉 덩관절 폄근을 강화시킨다. 체간과 하지에서의 닫힌 사슬 근력강화 운동은 엉덩관절 근육에만 활성화가 일어나는 운동이 아닌 체간과 하지의 모든 관절에서 활성화가 일어나며 근육간의 적절한 길이-장 력관계에 의한 길항적 이점을 가지고 있다.

체간과 하지의 안정은 요추 손상의 예방과 치료에 중요하며, 안정 을 위해서는 특정한 근육의 활성화가 중요한 것이 아니라, 요추를 감 싸고 있는 모든 체간근육과 하지근육의 협응 활동(co-activation)이 중 요하다. 체간의 안정과 관련된 근육은 국소근육과 대근육으로 구분 되며, 국소근육과 대근육의 사이에 조절된 작용은 척추의 안정화에 기여한다. 최근의 연구에서 슬링을 이용한 교각자세 운동은 닫힌 사 슬 체중부하운동으로 다관절운동이 가능하며, 슬링을 이용한 교각 자세 운동은 체간근육의 활성화에 효과적인 운동으로 제시하고 있 다. ${ }^{4}$ 이와 같이 여러 연구에 의해 슬링을 이용한 교각자세 운동의 장 점과 효과가 소개되고 있지만, 대부분의 연구들이 안정적인 지지면 에서의 운동과 불안정한 지지면에서의 운동, 혹은 다른 운동도구와 슬링운동의 비교 등 운동도구간의 연구들이었지만, 슬링을 이용한 교각자세 운동 시 정확한 근육동원을 위한 불안정 강도에 따른 효과 적인 운동방법에 관연 연구는 부족한 실정이다. 이에 본 연구에서는 체간의 안정화에 대한 연구를 하고자 근력강화운동의 한 방법으로 슬링을 이용한 교각자세 운동 시 불안정과 운동의 강도를 변화하기 위한 방법으로 슬링에 지지된 다리의 높이 변화에 따라 체간 폄근과 엉덩관절 폄근의 근활성도 차이를 비교하여, 보다 효율적인 운동방 법을 제시하고자 하였다. 본 연구의 목적은 바로누운 자세에서의 교 각 운동 시 슬링 스트랩의 높이가 몸통 및 엉덩 근육활성에미치는 영 향에 관하여 연구하고자 하였다.

\section{연구 방법}

\section{1. 연구 대상자}

본 연구 대상자는 2015년 8월에 대구광역시 소재 D대학교에 재학 중 인 건강한 성인 남성 17 명을 대상으로 자발적으로 실험참여에 동의 하고 본 연구의 목적과 방법에 대해 충분히 이해한 자로 하였다. 연구 에 영향을 미칠 만한 신경계 및 근골격계의 병력과 기능장애가 없는 자, 슬링운동이 가능한 자로 운동수행에 어려움이 없고 의사소통이 가능한 자, 교각자세 운동이 가능한 체간과 하지의 관절가동범위를 가진 자, 척수손상과 감염, 종양 등 기타 운동장애를 일으키는 정형 외과적, 신경학적 질환이 없는 자로 정하였다. 대상자의 일반적 특성 은 정상 성인남성 17 명으로 평균 나이는 25.5 세, 평균 신장은 $174.8 \mathrm{~cm}$, 평균 몸무게는 $70.2 \mathrm{~kg}$ 으로 평균 체질량지수(BMI) $22.9 \mathrm{~kg} / \mathrm{m}^{2}$ 이다.

\section{2. 실험 방법}

\section{1) 교각 자세에서의 슬링 운동}

바로누운자세에서 교각자세 운동을 실시하기 위해 슬링운동장비 (sling exercise tool. Redcord ${ }^{\circledR}$. Norway)를 사용하였으며, 보조도구로 양 다리를 지지하기 위하여 내로우슬링(narrow sling)을 사용하였다. 연구대상자는 바로 누운자세에서 교각자세 운동 시작자세 시 대퇴 부에 부착된 OB-Goniometer (Myrin ${ }^{\mathrm{TM}}$ OB-Goniometer, Kineman Enterprises, Norway)와 지면이 수평으로 이루는 각도를 $10^{\circ}, 20^{\circ}, 30^{\circ}$ 로 설 정하였을 때 각각의 스트랩의 높이를 Level I, II, III으로 구분하고 슬 링을 이용한 교각자세 운동을 유지하여 등척성 수축 동안 근활성도 를 기록하였다(Figure 1). 치료사의 시작' 구령과 함께 교각 자세 운동 을 실시하였으며 동작의 순서는 양 손을 양 옆으로 $30^{\circ}$ 정도 벌려 손 바닥이 아래로 향하게 하여 가지런히 내려놓고 두 다리를 슬링의 스 트랩 위에 올려놓은 후 무릎관절의 폄과 함께 무릎을 아래로 누르면 서 골반을 바닥에서 들어 올리도록 지시하였다. 대상자는 교각자세 운동 동작을 5 초간 유지하였으며, 5 초 동안의 운동을 1 회로 하여 3 회 반복을 통해 얻어진 근활성도의 평균값을 구하여 대표 값에 이용하 였다. 각 운동 사이에는 1 분간의 휴식시간을 제공하였다.

\section{2) 표면 근전도 측정}

근육의 활성도를 파악하기 위해 8채널 무선 표면 근전도 EMG-8 (Laxtha, Korea)를 사용하였으며, 은/염화은 $(\mathrm{Ag} / \mathrm{AgCl})$ 전극을 사용하 여 디지털 신호로 전환되어 수집된 각 근육 4 개의 채널의 표면 근전 도 아날로그 신호를 개인용 노트북에서 Telescan 소프트웨어를 이용 하여 처리하였다. 근전도 측정시 피부저항을 감소시키기 위해 전극 을 부착하기 전에 부착 부위에 털을 제거하고, 가는 사포로 피부의 각질을 제거한 다음, 소독용 알코올 솜으로 피부지방을 제거하였다.5 

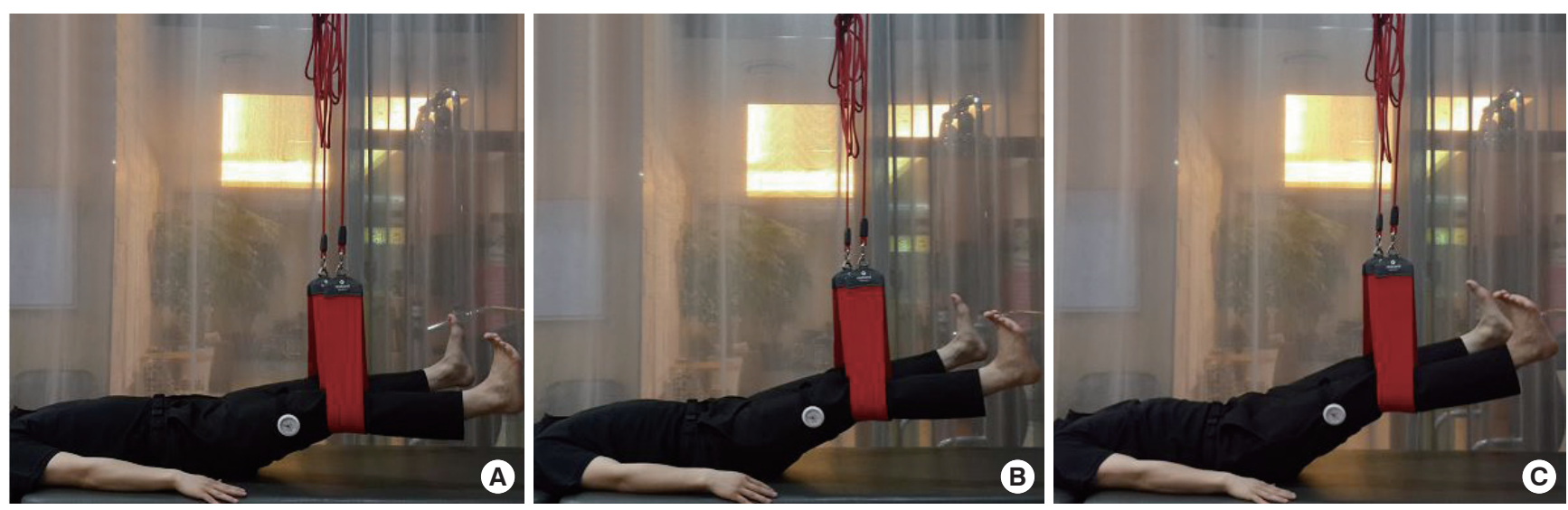

Figure 1. Experimental protocol for the bridging exercises. (A) Level I bridging exercise. (B) Level II bridging exercise. (C) Level III bridging exercise.

전극간거리는 노이즈를 최소화하고 최대한의 신호를 획득하기 위해 각각 근섬유 방향과 평행하게 전극 간 거리는 $2 \mathrm{~cm}$ 간격으로 부착하 였다. 전극의 부착 위치는 척추세움근(erector spinae)은 L2극돌기에서 $2 \mathrm{~cm}$ 수평하게 떨어진 지검의 근복부위에, 뭇갈래근(multifidus)은 L5 극돌기와 후상장골극 선상에, 큰볼기근은 대퇴골 대전자와 제 2 천골 추체 사이의 중간지점에 근육과 평행하게, 넙다리뒤근육은 슬와 주 름과 둔부 주름사이의 중간지점으로 하였다. 접지전극은 경골두 위 에 부착하였다.

근전도 장비와 연결된 노트북에서 각 각의 케이블과 연결관 근육 에 해당하는 채널을 지정하여 근전도 신호를 기록하였고, 수집된 신 호의 표본추출률(sampling rate)은 $1,024 \mathrm{~Hz}$ 로 하였다. 전기신호에 의 한 잡파 제거를 위해 주파수 대역폭(bandpass-filter)를 10-450 Hz로 설정하였고, 노치필터(Notch filter)는 $60 \mathrm{~Hz}$ 를 사용하였다. 기록된 근 전도 값을 정규화(Normalization)하기 위하여 근전도 부착 후 최대 수의적 등척성 수축(maximal voluntary isometric contraction)을 각 자 세에서 5 초간 3 회 반복 실시하여 MVIC 값을 측정하였으며, 시작과 마지막의 각 1 초를 제외하고 중간의 3 초 동안의 평균 근전도 값을 $100 \% \mathrm{MVIC}$ 로 정하여 5 초 동안의 근전도 자료를 제곱평균제곱근 (root mean square)으로 처리하였다. 근전도의 측정단위는 $\mathrm{uV}$ 로 기록 되었다.

\section{3) 통계 분석}

실험을 통하여 수집된 자료는 통계 분석을 위하여 상용 통계프로그 램인 SPSS ver. 22.0 프로그램(SPSS Inc, Chicago, IL, USA)을 이용하여 분석하였다. 기술통계 자료는 평균과 표준편차로 제시하였다. 각 근 육에서 세 가지 슬링 스트랩 높이에 따른 근활성도를 비교하기 위하 여 이요인 분산분석(two way ANOVA)를 실시하였다 또한 스트랩 높 이에 따른 근활성도의 비율을 비교하기 위해서는 일요인분산분석 (One way ANOVA)를 실시하였고, 사후분석을 위해 Bonferroni 방법
Table 1. Relative EMG activity ratios of local trunk muscles to global muscles during bridging exercises.

\begin{tabular}{lcccc}
\hline & Level 1 & Level 2 & Level 3 & $\mathrm{p}$ \\
\hline Multifidus/Elector spinae & $1.10 \pm 0.16$ & $1.19 \pm 0.16$ & $1.31 \pm 0.20$ & $0.00^{*}$ \\
$\begin{array}{l}\text { Gluteus maximus/ } \\
\text { Hamstring }\end{array}$ & $1.30 \pm 0.41$ & $1.49 \pm 0.49$ & $1.84 \pm 0.60$ & $0.00 *^{*}$ \\
\hline
\end{tabular}

${ }^{*} p<0.05$.

을 사용하였다. 통계학적 유의수준의 $\alpha=0.05$ 로 정하였다.

\section{결 과}

\section{1. 슬링 스트랩 높이와 근육에 따른 근활성도 비교}

슬링 트랩의 높이와 근육에 따른 근활성도를 비교한 결과 슬링 스트 랩의 높이, 근육, 슬링스트랩 높이×근육에 따라 유의한 차이가 있었 다 $(\mathrm{p}<0.05)$. 사후 검정 결과 척추세움근은 수준 3 이 수준 1 에 비하여 유의하게 근활성도가 높았다 $(\mathrm{p}<0.05)$ (Figure 2). 근다열근과 큰볼기 근에서는 수준 3 이 수준 1과 수준 2에 비하여 유의하게 높았고 ( $\mathrm{p}<0.05)$, 수준 2 는 수준 1에 비하여 유의하게 높았다 $(\mathrm{p}<0.05)$ (Figure 2). 그러나 넙다리뒤근육에서는 스트랩 높이가 높아짐에 따라 근활 성도가 높게 나타났지만 통계적으로 유의한 차이가 나지는 않았다 ( $>0.05$ ) (Figure 2).

\section{2. 슬링 스트랩의 높이에 따른 근육간 근활성도 비율 비교}

각 근다열근/척추세움근 근활성도 비율은 슬링 스트랩의 높이에 따 라 유의한 차이가 있었다 $(\mathrm{p}<0.05)$. 사후검정 결과 수준 3 이 수준 1 과 수준 2 에 비해 유의하게 높게 나타났으며 $(\mathrm{p}<0.05)$, 수준 2 가 수준 1 에 비해 유의하게 높게 나타났다 $(\mathrm{p}<0.05)$ (Table 1). 큰볼기근/넓다리뒤 근육 근활성도 비는 슬링 스트랩 높이에 따라에 유의한 차이를 보였 다 $(\mathrm{p}<0.05)$. 사후검정 결과 수준 3 이 수준 1 과 2 에 비해 유의하게 높게 나타났으며, 수준 2 가 수준 1 에 비해 유의하게 높게 나타났다(Table 1). 


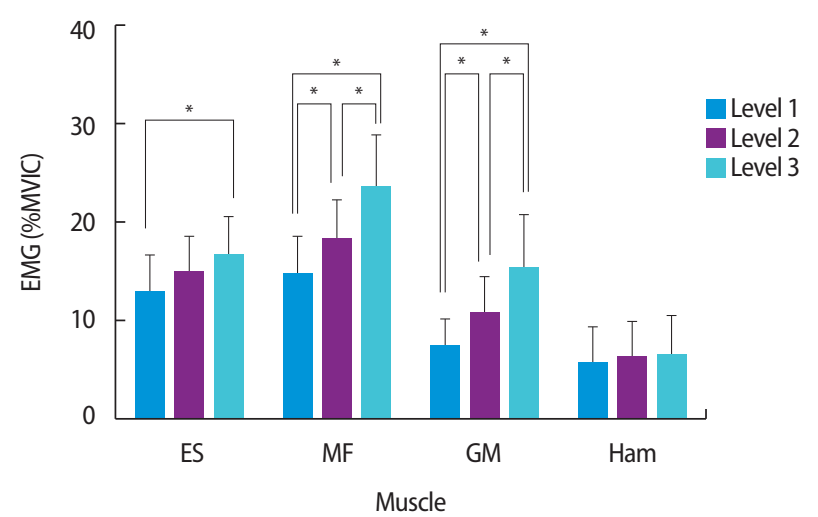

Figure 2. Comparison of muscle activation on sling strap height during bridging exercise.

ES: Erector spinae, MF: Multifedus, GM: Gluteus maximus, Ham: Hamstring.

${ }^{*} p<05$.

\section{고 찰}

임상에서의 교각 자세 운동은 체간 안정화 운동 프로그램으로 자주 사용되고 있으며, 불안정한 지지면 에서의 운동은 안정된 상태에서 의 운동보다 근육의 활성이 더 많이 일어나게 되고, 동적 균형을 증가 시켜 척추손상을 예방하고 치료할 수 있다고 보고되어 있다. 그리고 교각자세 운동은 임상에서 체간 안정화 운동으로 사용되고 있으며, 환자들이 편안함을 느끼고 통증이 줄어드는 운동이며, 대근육과 국 소근육이 협응하여 안정화를 얻을 수 있도록 한다.7 이 운동은 요통 환자의 요부 안정화를 위해 실시하며 분절 안정성과 움직임 간 근육 의 협응패턴을 재교육하는 것이 핵심인 운동이며, 건강한 사람의 중 립자세에서 교각자세 운동 시 척추세움근의 활성도는 감소하고, 체 간심부근육과 하지근육의 근활성도는 증가하며, 요통 환자의 경우 에도 불안정한 지지면에서의 교각자세 운동이 효과가 있다고 보고하 였다. 또한 이전의 연구에서는 안정화 운동을 할 때, 국소근육의 높 은 활성은 체간을 적절한 안정 상태로 유지한다고 하였다. ${ }^{9}$ 이에 본 연구는 체간근육의 활성화에 효과적인 슬링 기구를 이용하여 체간 안정화 운동으로 흔히 사용되는 교각자세 운동을 스트랩의 높이에 따라 어떠한 영향을 미치는지 알아보기 위하여 실시하였으며, 실험 에서는 체간과 엉덩관절의 폄근육의 근활성도와 각 근육간의 근활 성도 비를 확인하였다.

이전 연구에서 닫힌사슬 체중부하 운동을 슬링을 이용하여 점진 적으로 적용하였을 때 요통환자의 근력과 고유수용감각이 증가되었 으며, 교각자세 운동 시 지지면에 따라 체간근육과 하지근육의 근활 성도는 차이가 있다고 보고되었다. ${ }^{10}$ 또한 체간근육과 하지근육의 활 성화를 위해 불안정한 지지면에서의 운동을 추천하고 있다." 교각자 세 운동이 볼이나 바닥에서 교각자세 운동을 실시하는 것보다 뭇갈
래근과 척추세움근의 근활성도가 유의하게 증가하였는데, 이러한 관 점에서 체간 근육들의 근 활성 수준을 분석하는 것은 운동 처방과 강도 조절을 위해 중요하다.12,13 따라서 본 연구에서 실시된 교각자세 운동은 체간근육과 하지근육의 근력향상과 근육의 협응패턴을 개 선시키기 위해 시행되는 가장 보편화된 닫힌 사슬 근력강화운동으 로, 하지의 체중부하를 통한 큰볼기근과 넓다리뒤근육의 근력향상 을 통해 보행 시 입각기 단계를 준비할 수 있는 운동방법이며, 자세조 절능력 향상을 위해 흔히 적용되는 운동방법이다. ${ }^{4}$ 한편 최근 연구 에서는 운동을 할 때, 동시수축을 통해 활성화되는 근육들의 근활성 도 비를 제시하여, 역학적으로 주로 활성화되어야 하는 근육의 근활 성도가 상대적으로 크게 나타는 운동이 소개되고 있다." O'sullivan ${ }^{1}$ 은 국소근육의 독립적인 운동 시 대근육과 국소근육의 근활성도 비 에 대해 연구하였고, 유사하게 본 연구에서는 체간 근육들의 근활성 도 뿐만 아니라 대근육에 대한 국소근육의 근활성도 비를 연구하였 다. 본 연구에서는 체간근육의 대근육으로 척추세움근을, 국소근육 으로 뭇갈래근을 선정하였다. 뭇갈래근은 체간 안정화 운동에서 국 소근육으로 중요한 역할을 하며, 체간 폄근으로 작용하는 국소근육 중 표면근전도로 측정이 가능한 근육이기 때문에 국소근육으로 선 정하였다.

요추골반부에서 국소근육과 대근육의 잘못된 근육동원은 척추 분절에 부하되는 압력이 가해지며, 근골격계 문제를 야기할 수 있으 며, 대개 체간안정화는 국소근육의 분절 안정화와 대근육의 전체적 인 힘 생성 사이의 적절한 비율에서 체간근육의 협응패턴과 연관되 어져있다. ${ }^{15}$ 또한, 엉덩관절 폄 시 넓다리뒤근육의 과활성화는 엉덩관 절 폄근인 큰볼기근의 활성과 골반안정화에 기여하는 근육들을 억 제시킴으로 인해 근육동원패턴의 변화가 발생하여, 변형된 골반의 움직임 나타내고 요추골반부에 기계적 자극을 증가시켜 결국 허리 통증을 야기할 수 있다고 보고되고 있다. 따라서 허리통증환자의 치 료적 운동을 적용 시 넓다리뒤근육의 과활성화를 최소화하며 큰볼 기근의 활성을 증가시킬 수 있는 운동을 적용하는 것이 중요하다. 이 러한 연구를 바탕으로 본 연구에서는 체간 근육 뿐만아니라 엉덩관 절 폄근육인 큰볼기근과 넓다리뒤근육의 근활성도 비에 대해 같이 연구하였다. 연구결과 스트랩의 높이에 따른 교각자세 운동 시 스트 랩의 높이가 Level 수준 1에서 수준 3으로 증가할수록 요추와 골반 안 정화에 기여하는 엉덩관절 폄근인 큰볼기근과 뭇갈래근의 근 활성 도가 증가되는 것으로 확인되었고, 그 결과 뭇갈래근/척추세움근, 그 리고 큰볼기근/넓다리뒤근육의 상대적인 비가 증가된 것으로 확인 되었다. 선행 연구에서는 슬링에서의 교각자세 운동 시 스트랩의 높 이에 따른 근활성도에 차이가 있으며, 체간근육의 활성화를 위해 스 트랩의 높이가 낮은 높이 보다는 높은 높이에서의 운동이 체간근육 의 근활성도에 유의한 차이가 있지만, 다양하지 못한 실험 조건으로 
인해 임상적으로 적용되기에는 한계가 있다고 보고하고 있다. ${ }^{16,17}$ 본 연구에서는 스트랩의 높이를 3 가지 단계로 구분하여 실험하였으며, 그 결과 유의한 값을 얻을 수 있었다. Lee 등15의 선행 연구에서는 슬 링에서의 교각자세 운동 시 스트랩의 높이변화에 따른 근활성도의 유의한 차이는 있었지만 다양하지 못한 실험 조건으로 인해 임상적 으로 적용되기에는 한계가 있다고 보고하고 있다. 한편 본 연구에서 는 스트랩의 높이를 임상적으로 적용하기 쉬운 3 가지 단계로 구분하 여 실험하였으며, 슬링을 이용한 교각자세 운동을 허리통증 환자의 치료적 운동 목적으로 적용 시 수준 3 의 스트랩 높이가 근육의 선택 적 동원과 안정성 운동을 위한 접근법으로 활용될 수 있을 것이다.

본 연구에서는 안정화 운동 방법으로 슬링을 이용한 교각자세 운 동을 적용하여 교각자세 운동 시 체간 및 하지근육의 근활성도 차이 에 대한 자료를 제시하고 있다. 본 연구의 제한점은 적은 실험대상자 로 인하여 일반화하기에는 다소 어렵다는 점과 좀 더 다양한 높이에 서의 실험이 이루어지지 못했다. 그러므로 추후 연구에서는 이러한 점을 고려하고 실질적인 임상 적용을 위해서는 다양한 증상과 장애 를 가지고 있는 환자들을 대상으로 슬링을 이용한 교각자세 운동의 효과를 살펴보는 연구가 필요하다고 생각된다. 또한 체간 안정성과 하지 근육의 선택적 강화를 위한 근육간의 근활성도 비율에 대해 좀 더 다양하게 연구할 필요가 있을 것이다.

\section{ACKNOWLEDGEMENTS}

This work was supported by research grants from the Catholic University of Daegu in 2013

\section{REFERENCES}

1. O'Sullivan PB. Masterclass. Lumbar segmental 'instability': Clinical presentation and specific stabilizing exercise management. Manual Therapy. 2000;5(1):2-12.

2. Kim GH, Choe HS, Lee HI et al. The effects of scapular stabilization exercise on dynamic standing balance in stroke patients J Korean Soc Phy Ther 2014;26(1):15-20.
3. LaFree J, Mozingo A, Worrell T. Comparison of open kinetic chain knee and hip extension to closed kinetic chain leg press performance. Journal of Sport Rehabilitation. 1995;4(2):99:1-07.

4. Jinsik P, Sangyong L, Gak H. The effects of a bridge exercise with vibration training and an unstable base of support on lumbar stabilization. Journal of Physical Therapy Science. 2015;27(1):63-53.

5. Ji Hae K, Young Eok K, Sea Hyun B et al. The effect of the neurac sling exercise on postural balance adjustment and muscular response patterns in chronic low back pain patients. Journal of Physical Therapy Science. 2013;25(8):1015-19.

6. Arokoski JP, Valta T, Airaksinen O et al. Back and abdominal muscle function during stabilization exercises. Archives of Physical Medicine \& Rehabilitation. 2001;82(8):1089-98.

7. Stevens VK, Coorevits PL, Bouche KG et al. The influence of specific training on trunk muscle recruitment patterns in healthy subjects during stabilization exercises. Manual Therapy. 2007;12(3):271-99.

8. Kumar S, Narayan Y. Torque and emg in isometric graded flexion-rotation and extension-rotation. Ergonomics. 2001;44(8):795-813.

9. Hodges PW. Is there a role for transversus abdominis in lumbo-pelvic stability? Manual Therapy. 1999;4(2):74-86.

10. Danneels L, Coorevits P, Cools A et al. Differences in electromyographic activity in the multifidus muscle and the iliocostalis lumborum between healthy subjects and patients with sub-acute and chronic low back pain. European Spine Journal. 2002;11(1):13-9.

11. Kim SY, Kim SY, Jang HJ. Effects of manual postural correction on the trunk and hip muscle activities during bridging exercises. Physiotherapy. 2015;101, Supplement 1:e752-e3.

12. Kang H, Jung J, Yu J. Comparison of trunk muscle activity during bridging exercises using a sling in patients with low back pain. Journal of Sports Science \& Medicine. 2012;11(3):510-5.

13. Lehman GJ, Hoda W, Oliver S. Trunk muscle activity during bridging exercises on and off a swissball. Chiropractic \& Osteopathy. 2005;13(7): $1-8$.

14. O'Sullivan SB, Schmitz TJ, Fulk G. Physical rehabilitation. FA Davis, 2013.

15. Marshall PW, Murphy BA. Core stability exercises on and off a swiss ball. Archives of Physical Medicine \& Rehabilitation. 2005;86(2):242-9.

16. Lee D, Park J, Lee S. Effects of bridge exercise on trunk core muscle activity with respect to sling height and hip joint abduction and adduction. Journal of Physical Therapy Science. 2015;27(6):1997-9.

17. Shin HK, Ryu YU. The effects of seat surface inclination on the onset of muscle contraction during sit-to-stand healthy adults. J Korean Soc Phys Ther. 2012;24(6):384-7. 